\title{
Disaster Risk of Landscape-Rockfall in Danxia Landform of Kongtong Mountain
}

\author{
Yutian Ke, Shouyun Liang, Zhuo Chen \\ College of Civil Engineering and Mechanics, Lanzhou University, Lanzhou 730000

\section{崆峒山丹霞地貌危岩景观的灾害风险}

\author{
柯雨田, 梁收运, 陈卓 \\ 兰州大学土木工程与力学学院, 兰州 730000, 中国
}

\begin{abstract}
Kongtong Mountain national geopark is characterized by Danxia landform. Lots of strange shaped unstable rocks emerged in the Danxia landform areas, not only do they have great ornamental and aesthetic value but also are potential geological disasters. During the formation process of landscape-rockfall, differential weathering, water erosion, biological deposition, freezing thawing and chemical element migration are contributed to the fantastic shapes. While human activities, earthquake, gravity unloading and root splitting are the major reasons for the failures. The complicated geological environment makes the main scenic spots of high risk, so the protection and management of unstable rocks is very important to the development of the geopark, but it is also a big challenge due to the high technical difficulty. To collect comprehensive information of the stability of unstable rocks, detailed investigation should be conducted and all-time digitalized monitoring facility on the stability should be equipped on major spots. Moreover, the irreversibility and the generation of secondary geological disaster during damaging process as well as the development sustainable problems of prevention and protection should be taken into particular considerations.
\end{abstract}

Keywords: Kongtong Mountain; Danxia landform; Landscape-Rockfall; Potential disaster

\section{摘要}

崆峒山是以丹霞地貌景观为特色的国家地质公园, 发 育有大量造型奇特的不稳定岩体, 它们不仅有较高的 旅游观光和美学欣赏价值, 同时也是一类破坏性较大
的潜在地质灾害, 集景观性与灾害性于一体。在景观 危岩的形成过程中, 差异风化、流水侵蚀、生物沉积、 冻融作用、化学迁移等多因素耦合是塑造其奇特表面 形态的主要因素, 而人类工程活动、地震、重力卸荷 以及根䢃作用易造成其失稳。对危岩景观的建设与保 护是地质公园发展的一项重要内容, 也是景区危岩灾 害治理的一个难题, 需对景区范围内危岩开展详细勘 察, 并对主要危岩点的稳定性进行系统地数字化实时 监测, 并注重其破坏发生时的不可逆性、次生灾害性 和保护的可持续发展性。

关键词: 崆峒山; 丹霞地貌; 危岩景观; 潜在灾害

1. 引言

崆峒山地处甘肃省陇东地区, 是古丝绸之路西出 关中之要塞, 不仅有丰富奇特的地质遗迹资源, 同时 宗教文化文明避迩, 人文底蕴深厚, 被誉为 “陇东黄 土高原上的一颗明珠”。地质遗迹是地球内力地质作 用和外力地质作用综合过程而形成的地质现象, 也是 最重要、最珍贵的自然遗产 [1]。随着人类工程活动 的深入和地质环境本身的影响, 地质遗迹易遭受破坏, 因此需要对其进行深入的管理和保护, 这也是国内外 关于地质遗迹开发与利用的共识[2-4]。地质遗迹范围 内地质灾害也呈多样性, 其中危岩分布较广, 在丹霞 地貌非常发育, 柱廊状丹霞上的岩柱也是危岩的一种, 不仅具有极高的美学价值也具有灾害性。这类集景观 性和灾害性于一体的危岩被称为景观危岩, 在其他类 型地质遗迹中也普遍存在, 如雅丹、喀斯特和石林等 ${ }^{[5]}$ 。姜伏伟、郭福生等对龙虎山丹霞地貌的危岩景观 进行了较为详细的调查研究, 提出了危岩景观的分类 方案, 给出了景区危岩防治的合理建议[5-7]。陈保林 对广东丹霞山鳄鱼爬山危岩体地质灾害点进行了变 形监测[8], 欧阳杰探究了丹霞山崩岩的空间分布 [9]。 
Risk Analysis and Crisis Response in Big Data Era (RAC-16)

黄进调查显示中国有 1003 处丹霞遍布 28 个省市跨越 14 个气候区 [10], 但对丹霞类地质遗迹的危岩处置仍 处于初步阶段。对崆峒山危岩的景观性和灾害性进行 系统的研究不仅服务于 “一带一路”, 促进景区可持 续性发展, 也可丰富中国丹霞理论研究。

\section{2. 危岩形成的地质环境条件}

崆峒山（包括后峡、香山、五台-隍城、弹筝湖、 西山、十万沟-大阴山以及太统山等七个地质旅游景 区，如图 1 所示), 地处甘肃省平凉市西侧, 总面积 约 $83.6 \mathrm{~km}^{2}$ 。丹霞地貌在后峡、香山、五台-隍城、弹 筝湖等四个地质旅游景区非常发育。丹霞地貌上有非 常丰富的危岩景观, 其形成是个相对较为漫长的过程, 地质条件的作用很大。

\section{2 地层岩性}

崆峒山丹霞成景的主要地层为三叠系 $\left(\mathrm{T}_{3}\right)$ 和白 严系 $(\mathrm{K})$, 呈现出丹霞地貌中罕见的灰色或浅紫红 色。三叠系地层为上三叠系延长群地层 $\left(\mathrm{T}_{3 \mathrm{yn}}\right)$, 本区 仅见上三叠系延长群下亚群和中亚群, 出露在崆峒山 中部, 以平行不整合的接触关系覆于二叠系之上, $\mathrm{T}_{3 \mathrm{yn}}$ 地层是组成崆峒山丹霞地貌景观的重要部分, 是 我国发育最好的一处。白严系地层为下白严系三桥组 $\left(\mathrm{K}_{1}{ }^{\mathrm{s}}\right)$ 和和尚铺组 $\left(\mathrm{K}_{1}{ }^{\mathrm{h}}\right)$ 地层, 不整合覆于二叠系 和三叠系之上, 主要分布在崆峒山山顶位置。 $\mathrm{K}_{1}{ }^{\mathrm{s}}$ 分 布广泛, 是形成傧峒山丹霞地貌景观的最主要地层, 钽质胶结, 大部分硅化、层理难辨, 岩性坚硬, 该套 地层厚度 3 850m, 砾石成份复杂, 以灰岩、石英砂 岩为主, 但胶结不均匀, 磨圆度自下而上由棱角、次

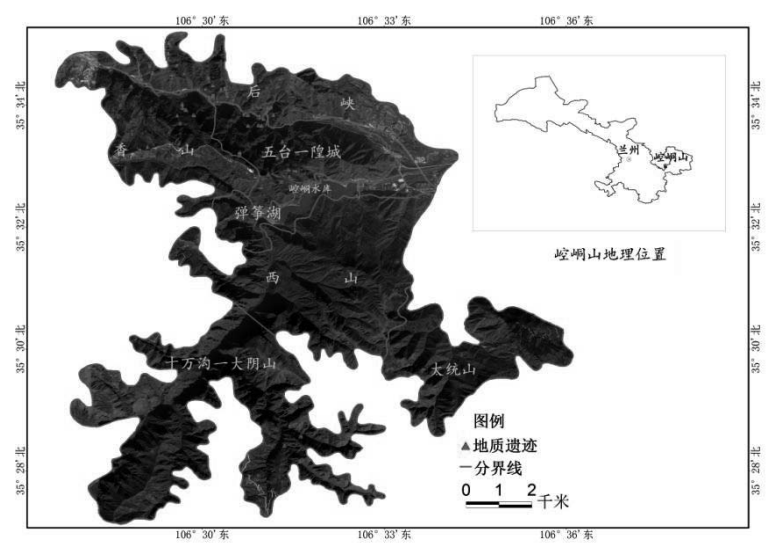

图 1. 崆峒山国家地质公园区域规划图

\section{1 地形地貌}

园区在自然地理景观上属黄土高原中山山地地 貌, 峰丛、峰林、石峰、崖壁、岩洞是其典型的丹霞 地貌类型。其地势西高东低, 海拔高程 1500-2234m, 沟谷深切, 两岸陡壁高差 500-750m, 山体坡度较大, 一般从大于 $50^{\circ}$ 到接近垂直。危岩体在陡峭的斜坡地 形及人类工程活动形成的高陡边坡容易发生[11]。泾 河的一级支流胭脂河由后峡 (胭脂川) 流经公园, 源 于六盘山的米缸山, 其它沟谷多为季节性间歇流水沟 谷, 整体水系较为发育。危岩险峻的地形地貌条件和 地表径流的作用为危岩的形成提供了有利的发育条 件。
棱角向次浑圆状、浑圆状逐步过渡。这也是危岩出露 的优势地层, 91 处危岩中有 82 处分布在三桥组; $\mathrm{K}_{1}{ }^{\mathrm{h}}$ 出露在西部边缘地带, 分布面积较小, 与 $\mathrm{K}_{1}{ }^{\mathrm{s}}$ 为连续 沉积。

\section{3 地质构造}

崆峒山地区在大地构造位置上处于北祁连褶䏢 带东缘, 鄂尔多斯盆地西侧, 贺兰褶皱带的南段, 是 祁吕山字型构造的脊柱, 处于华北地台的西南边缘。 区域内表现为三条平行的褶诐和冲断层组成的复式 背斜, 其构造线为南北或北偏西走向由于受区域地质 构造的影响, 区内节理发育, 发育较好的节理有五组, 走向北西三组, 走向北东两组最为发育, 构成 “ $\mathrm{X}$ ” 型。区域地质构造现象较为复杂, 地壳运动强烈, 有 


\section{Risk Analysis and Crisis Response in Big Data Era (RAC-16)}

利于崆峒山节理的发育和裂缝的扩大, 从而加速了危 岩的发育, 也增大了其不稳定性。如三珠洞天, 其洞 口受南北向和东西向两组垂直节理控制。

\section{3. 危岩景观的致灾性}

\section{1 危岩景观形态的造型因素}

在漫长的地质过程中, 地质条件和风化营力是危 岩形成的主要因素[12], 而风化营力对危岩的形态塑
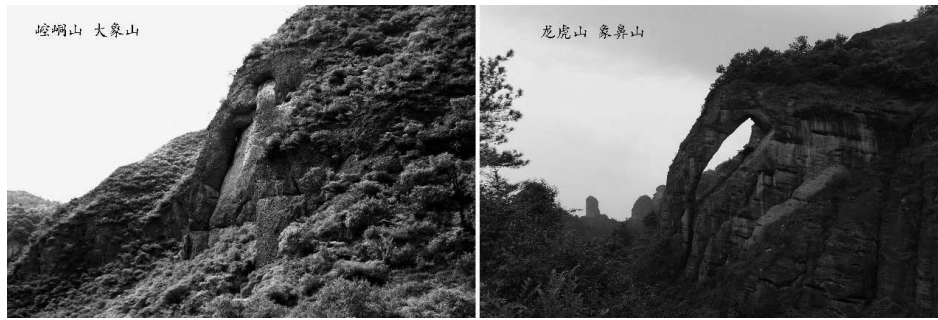

图 2. 傧峒山与龙虎山丹霞地貌读景

危岩发育的多套地层岩性差异较大, 特别是白严 系巨厚砾岩, 往往夹有薄层石英砂岩和泥岩, 而且砾 岩砾石成分以灰岩为主, 抗溶蚀能力弱, 不同岩性的 抗风化作用不同。例如 “方山” 景点上面是砾岩, 岩 石坚硬, 下部是砂岩, 相对较软, 则形成了上部大, 下面小的类似 “方山” 的地质景观。又如两层砾岩之 间夹了一层较薄的泥岩, 泥岩相对软弱, 抗风化能力 弱, 易风化剥落, 而砾石抗风化能力强则形成了蘑菇 石, 进一步演化则会形成摇摆石。差异风化是形成此 类景观的主要造型因素。傧峒山地区降雨较为丰富, 但蒸发量更大, 水的冲蚀和溶解将岩体表层的软弱物 冲刷带走; 同时强烈的蒸发对岩体实际上构成若干次 强烈的干湿循环, 影响岩体的力学性质, 从而破坏岩 体的内部结构, 造成微孔隙增加和发育, 在风化剥蚀、 冻融作用、差异风化、重力卸荷以及化学溶蚀等作用 下形成其表面形态的光怪陆离, 主要表现在小孔洞和 大型洞穴的发育。砾岩内部裂隙水及孔隙水常年的冻 融循环易造成岩体微裂缝的增大从而引起岩体结构 破坏, 胶结物及岩体内部化学元素在水的作用下易发 生迁移, 在部分洞穴中甚至有轻微的岩溶喀斯特现象。 而崆峒山独有的泼墨岩是由于藻类在湿润半湿润气 候下的岩壁上生长和沉积形成, 表现为赤壁上黑色的 平行条带。

差异风化、流水侵蚀、生物沉积、冻融作用和化 学迁移等风化营力虽然主要塑造了微地貌和危岩的 形态, 但其实也是一类影响较小的致灾因子。
造影响至关重要, 正因为其对岩体表面的雕刻作用, 形成独特的地质景观。如位于后峡的大象山, 岩柱紧 贴于岩壁上, 但中间已部分镂空, 如同大象的鼻子活 灵活现, 这与江西省龙虎山丹霞地貌的象鼻山有异曲 同工之妙, 大自然的鬼斧神工让人称赞不已 (图 2)。 对崆峒山丹霞危岩景观造型的主要因素有差异风化、 流水侵蚀、生物沉积、冻融作用和化学迁移。

\section{2 危岩景观的致灾因子}

景区内岩体的失稳主要受地震、人类工程活动、 重力卸荷和根䢃作用的影响, 一般呈大型砾岩在山坡、 沟谷段分布, 或在坡底呈碎屑状堆积。

地震的破坏力巨大 $[13]$, 平凉历史上受过多次强 烈地震的影响。如图 3 所示, 三次历史地震为 2008 年 $M \mathrm{~s} 8.0$ 级 “ 5.12 ” 汶川地震、 1920 年 $M \mathrm{~s} 8.5$ 级海原 地震以及 1654 年 $M \mathrm{~s} 8.0$ 级天水地震的等震线图, 三 次地震破坏性巨大, 引发了大量规模巨大的次生地质 灾害, 强烈地改造了地表形态。依等震线图所示, 崆 峒山国家地质公园处于海原地震和天水地震的 VII 度烈度区, “5.12”汶川地震的 VI 度烈度区。“ 5.12 ” 汶川地震诱发了平凉市大量小型崩塌和滑坡灾害, 其 中崆峒区受灾较严重[14], 地震会对崆峒山岩体的稳 定性产生较大影响, 如二郎石和胭岩插翠等崩积型砾 岩地质遗迹可能都是历史地震诱发危岩崩塌而形成 (图 4)。

人类工程活动对周围岩体的扰动较大, 随着大量 基础设施如人行通道和公路的建设, 以及景区的不断 开发建设, 地质环境受到了较大的影响。弹等湖的绕 湖步行通道旁的三叠系岩层高陡边坡, 后峡平泾公路 和峰沟盘山公路旁的白严系岩层高陡边坡都是人为 扰动的后果。后峡岩层倾向顺坡向, 且多处为大型崩 塌堆积陡坡, 稳定性较差; 鳄鱼山受峰沟盘山公路建 设影响, 底部大量岩体被开挖, 顶部岩柱受扰动, 也 
Risk Analysis and Crisis Response in Big Data Era (RAC-16)

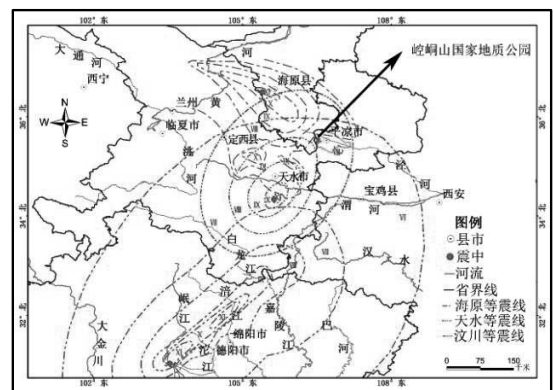

图 3. 历史地震等震线图

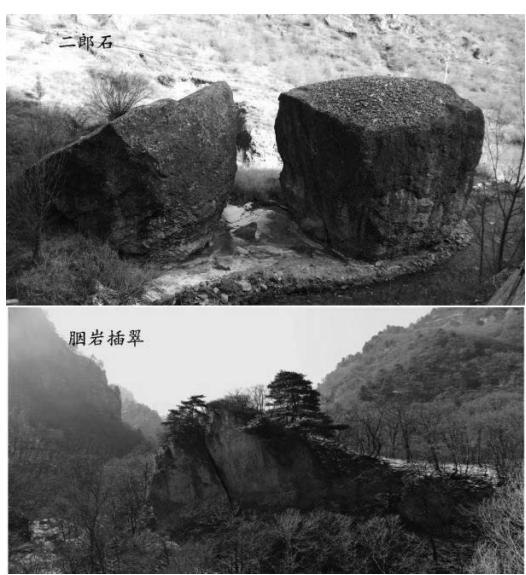

图 4. 崩积岩体地质遗迹景观

易出现失稳, 峰沟另一侧已有大型岩体崩落, 堆积于 沟底（图 5)。

在地质作用和人工开挖下, 岩体发育了很多卸荷 裂缝, 这些裂缝在重力作用下会进一步张开或位移, 最终发生崩落。如后峡公路旁的刀䢃石, 多条节理裂 缝将岩体切割, 中间形成多块不稳定岩体; 候旨沟崖 壁上纵向与横向节理密集发育, 受两者共同切割, 岩 壁上附着有多块不稳定岩体, 在重力作用下, 贴向崖 壁的主控结构面扩大易造成失稳 (图 6 左); 在新发 现的一处潜在地质遗迹中, 有大型不规则岩块贴于崖 壁上, 受控于两组主结构面, 重力牵引下易卸荷崩塌 (图6 右)。

崆峒山森林覆盖率达到 $62.6 \%$, 树木的根䢃作用 的影响较为显著, 松树在悬崖峭壁上从生是崆峒山的 一大特色。如图 6 左图可知树木的生长规律, 基本沿
节理裂隙中生长, 崖顶大面积分布。密集复杂而强劲 的根系沿裂缝向内生长, 会使原有的裂隙张开扩大, 进一步破坏岩体的结构, 加剧危岩体的变形。

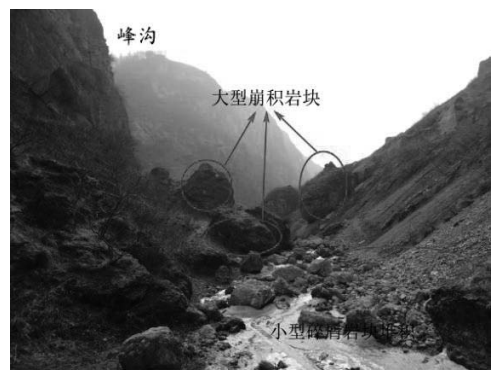

图 5. 峰沟崩积岩块

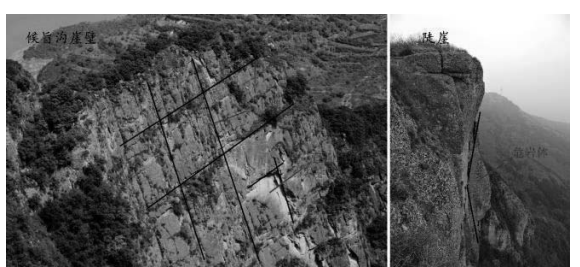

图 6. 崖壁危岩体示意

\section{4. 危岩景观的潜在威胁与保护}

\section{1 潜在威胁}

初步调查了崆峒山丹霞地貌发育的后峡、香山、 五台一隍城、弹筝湖等四个地质旅游景区区域范围内 的 91 处危岩点, 其中 37 处为已规划地质遗迹点, 54 处为潜在地质遗迹点和灾害点。后峡最为密集有 53 处, 五台一隍城 21 处, 香山 12 处, 弹笔湖 5 处。而 五台一隍城以及香山是旅客活动的核心景区, 人形天 梯旁侧基本为高陡岩壁; 而贯穿后峡的泾平公路位于 峡谷, 是连接泾川县和平凉市的交通要道, 同时有青 兰高速穿过, 车流量巨大, 旅客经过时可以欣赏峡谷 两侧雄伟壮丽让人叹为观止的丹霞风光 (图 7)。危 岩景观的潜在灾害性对旅客的生命安全以及景区的 可持续发展构成了较大的威胁。

危岩景观的形态千奇百怪, 稀有独特而具吸引力, 是山地旅游景区可持续发展的重要保证, 但是需要被 合理的开发利用。如丹霞赤壁、大象山、麦垛山、风 动石、石林佛塔、通天洞、龟蛇对峙等都是或者发育 有不同程度的危岩, 但也是多数游客驻足观赏的景点。 危岩景观的潜在灾害性主要体现在两个方面, 一是对 


\section{Risk Analysis and Crisis Response in Big Data Era (RAC-16)}

景观资源的损失, 二是构成岩崩造成人员伤亡和基础 设施毁坏。由弹筝湖景区向中台的上山天梯附近可见 一条明显的乱石沟, 沟中从上往下错落着多块大型砾 石岩块, 且谷底仍可见岩块堆积, 说明崖顶危岩曾发 生大规模群集性崩塌。若此类岩崩再次发生, 弹笔湖 观景通道作为其他线路选择的必经之道会被乱石破 坏, 灾害的发生会造成旅游价值的显著降低。雷声峰
南北两侧均被近东西向的断裂所切, 形成东西向延伸 的岩墙, 岩墙上节理裂缝发育, 局部有岩洞出露, 若 此处发生失稳, 人文和地质遗迹景观会遭到严重的破 坏, 同时向下滚落的岩体也可能摧毁其他景观, 造成 次生灾害。
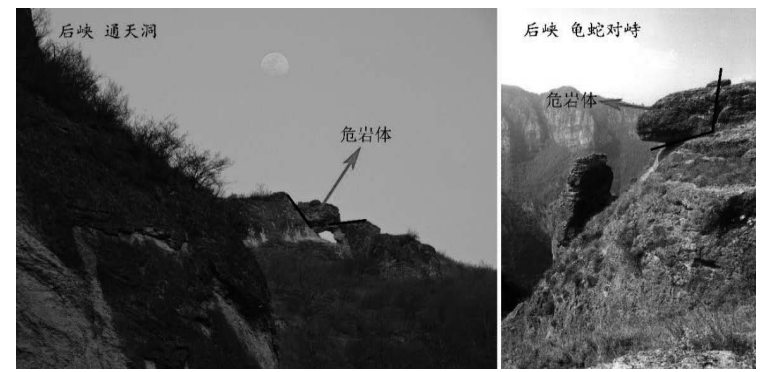

图 7. 后塽危岩景观

\section{2 保护与防治措施}

非景观性危岩因其对景区的潜在威胁而具有特 殊性，防治上应维持景区的美学价值和可持续发展。 通过对危岩景观的防治来保护旅客的安全对提升景 区的旅游价值非常重要。危岩失稳时爆发突然、能量 较大、破坏性强, 且其在运动过程中碎化并易诱发次 生灾害的发生, 具有连带效应。景区危岩灾害的处置 需注重维护景区整体的美观性; 对于景观危岩, 更要 做到维持原样, 这是在景区内开展该项工作的难点。

对于景区危岩的治理, 应从岩体本身、运动路径 以及诱发因素三个方面进行。并根据崆峒山危岩体的 岩性、变形破坏特征、致灾因子、环境条件及景观特 征等针对性地选择合理的治理方案。从岩体本身, 需 增强自身的稳定性, 减少周围环境对其的扰动; 从运 动路径, 崆峒山景区以及地质遗迹高低分布的空间格 局明显, 需阻挡崩塌岩体与景观点之间的接触, 限制 其运动范围从而减少危害性; 从诱发因素, 人类工程 活动、地震、重力卸荷、根辟影响很大, 应减小工程 建设对周围岩土体的扰动, 在不影响美观性的前提下 对非景观危岩体进行清除。特别对于景观危岩, 需着 重注意破坏发生时的不可逆性、次生灾害性和保护的 可持续发展性。不可逆性指危岩类地质遗迹遭到破坏 是单向发展的, 一旦遭到破坏即意味着不可修复或者 人工修复无效; 而其次生灾害性是指岩体在运动过程 对其他地质遗迹的损坏, 诱发更多危岩体失稳。对危 岩景观的保护应综合考虑其美学价值和科学价值, 既
要提高其稳定性也要维持其原来的景观造型, 因此需 要格外注意施工和修补工艺, 这一方面需要进行深入 探究。危岩的失稳具有突发性, 对景区内危岩按规模、 形态、失稳类型、潜在危险级别、景观保护级别分类, 并据此进行分级数字化实时监测, 全面获取危岩裂缝 张开、沉降变形的相关数据, 为进一步开展有效的保 护和治理手段提供依据。

\section{5. 结论}

崆峒山丹霞地貌是发育在半湿润区的典型丹霞 地貌, 景观危岩作为成景系统重要的一部分, 具有很 高的旅游观赏价值, 但同时其潜在灾害性威胁了景区 的可持续发展。独特的地质环境作用促成了危岩的形 成与发育, 地质条件和风化营力不同程度地影响着危 岩的成景过程和致灾过程。其光怪陆离的形态主要受 差异风化、流水侵蚀、生物沉积、冻融作用和化学迁 移等风化营力的雕刻作用; 而其失稳的主控影响因子 为人类工程活动、地震、重力卸荷和根䢃作用。

为提升傧峒山国家地质公园的旅游价值, 应对景 区内的危岩采取合理有效的治理和保护措施, 不仅要 预防危岩灾害, 同时不能对地质资源与旅游区的美观 性构成破坏。尤其在对景观危岩的治理和保护过程中, 施工和修补工艺非常重要, 需要对其进行深入地研究。 景区应建立危岩分类系统, 并据此对危岩裂缝张开、 沉降变形进行分级数字化实时监控, 为实现崆峒山丹 霞地貌地质遗迹资源的可持续开发与利用提供必要 手段。 
Risk Analysis and Crisis Response in Big Data Era (RAC-16)

\section{Acknowledgements}

This study was supported by technical industrialization project of Gansu Science Academy (research on geological relics and the key developing techniques in Gansu province).

\section{致谢}

本文得到甘肃省科学院科技产业化项目“甘肃省地质 遗迹资源现状及其开发关键技术研究” 资助。

\section{参考文献}

[1] 赵汀, 赵逊. 地质遗迹分类学及其应用. 地球学 报, 2009, 30(3):309-324.

[2] Dong H, Song Y, Chen T, et al. Geoconservation and geotourism in Luochuan Loess National Geopark, China. Quaternary International, 2013, s 334-335(12):40-51.

[3] Wang L, Tian M, Wang L. Geodiversity, geoconservation and geotourism in Hong Kong Global Geopark of China. Proceedings of the Geologists Association, 2015, 126(3):426-437.

[4] Burlando M, Firpo M, Queirolo C, et al. From Geoheritage to Sustainable Development: Strategies and Perspectives in the Beigua Geopark (Italy). Geoheritage, 2011, 3(2):63-72.

[5] 姜伏伟, 郭福生, 姜勇彪, 等. 山地风景区景观危
岩灾害研究. 工程地质学报，2010，18(suppl.): 445-449.

[6] 姜伏伟, 郭福生, 姜勇彪, 等. 龙虎山丹霞地貌危 岩景观成因及保护。山地学报, 2011, 29(2): 202-209.

[7] 郭福生, 姜伏伟, 胡中华,等. 丹霞地貌危岩景观 分类及可持续开发对策——龙虎山景区为例. 山地学报, 2012, 30(1):99-106.

[8] 陈保林. 丹霞山风景区鳐鱼爬山危岩体变形监测. 安全与环境工程, 2011, 18(4):7-10.

[9] 欧阳杰. 广东丹霞山崩岩空间分布的初步研究. 地球, 2014(3).

[10] 黄进, 陈致均, 齐德利. 中国丹霞地貌分布(上). 山地学报, 2015(4):649-673.

[11] 刘卫华, 黄润秋, 裴向军. 高陡边坡危岩体发育 特征研究. 全国工程地质学术年会. 2011 .

[12] 杨转运, 刘会, 叶四桥, 等. 危岩体发育的典型 环境条件分析。公路交通技术，2005，12(6): 106-110.

[13] Yan J, Li S, Bai J, et al. The Spatial Symmetry Axis of Earthquake Hazard in China. Journal of Risk Analysis \& Crisis Response, 2013, 3(1): 5964.

[14] 姚文波, 刘文兆, 侯角坚. 汶川大地震陇东黄土 高原崩塌滑坡的调查分析. 生态学报, 2008, 28(12): 5917-5926. 